\title{
COEXISTENCE OF MYOCARDIAL INFARCTION WITH NORMAL CORONARY ARTERIES AND A LEFT CIRCUMFLEX ARTERY ANOMALY ORIGINATING FROM THE RIGHT CORONARY ARTERY WITH A BRIDGE IN THE LEFT ANTERIOR DESCENDING ARTERY
}

doi: $10.1590 / \mathbf{S 1 8 0 7 - 5 9 3 2 2 0 0 9 0 0 0 7 0 0 0 1 6}$

Yusuf Selcoki, Okan Er, Beyhan Eryonucu

\section{INTRODUCTION}

Congenital anomalies in the origin, course or distribution of the epicardial coronary arteries are found in 1 to 2 percent of the population. Asymptomatic coronary artery anomalies are generally diagnosed incidentally by routine coronary angiography or during autopsy. ${ }^{1}$ Approximately $80 \%$ of congenital anomalies of the coronary arteries are benign, while $20 \%$ of coronary artery anomalies produce life threatening symptoms, including arrhythmias, syncope, myocardial infarction or sudden death. These anomalies are especially dangerous when they courses between the aorta and the main pulmonary artery.

It is not yet possible to determine the causes of a particular patient's infarction. The valvular mechanism has been suggested to result from angulations at the arterial origin or from the compression of the artery between the aorta and the pulmonary artery during exercise. ${ }^{2}$ In some cases, spasms of the abnormal coronary artery (possibly due to endothelial damage) or arteriosclerosis have been considered to be the reasons for coronary arterial occlusion. ${ }^{3-4}$

We report a patient with two coronary anomalies, a left circumflex coronary artery (LCX) originating from the proximal right coronary artery (RCA) and a muscular bridge in the left anterior descending (LAD) midportion, who

Department of Cardiology, Faculty of Medicine, Fatih University - Ankara, Turkey.

Email: yussel1971@hotmail.com

Tel: 903124098888 underwent successful fibrinolytic therapy for an inferolateral myocardial infarction.

\section{CASE DESCRIPTION}

A 37-year-old man presented with typical resting chest pain. Laboratory tests at admission revealed that the aspartate aminotransferase/alanine aminotransferase and lactate dehydrogenase levels were normal. The creatine kinase (CK) level was $123 \mathrm{IU} / \mathrm{L}$ at admission, $1444 \mathrm{IU} / \mathrm{L} 4$ hours after admission, 1972 IU/L 8 hours after admission, and 1842 IU/L 12 hours after admission. The creatine kinase-MB level was $12 \mathrm{IU} / \mathrm{L}$ at admission, $159 \mathrm{IU} / \mathrm{L} 4$ hours after admission, 246 IU/L 8 hours after admission, and 202 IU/L 12 hours after admission. The initial electrocardiogram (ECG) showed a normal sinus rhythm (77/minute) and a 2-3 mm ST segment elevation at DII, DIII, aVF, V5 and V6 derivations with reciprocal ST segment depression at DI, aVL, V1 and V2 derivations (Figure 1). At that time, the patient was diagnosed with an acute inferolateral ST elevated myocardial infarction (STEMI). First, he was given $300 \mathrm{mg}$ acetylsalicylic acid orally, followded by 5 $\mathrm{mg}$ sublingual isosorbide dinitrate, and finally unfractioned heparin in a $5000 \mathrm{U}$ IV bolus. The patient's pain was reduced after the injection, but he still had discomfort in his chest. He was immediately given a 90 minute treatment of tissue plasminogen activator (tPA) and concurrent $1000 \mathrm{U} /$ hour unfractioned heparin infusion. The troponin $\mathrm{T}$ levels were $1.82 \mathrm{ng} / \mathrm{ml}, 2.61 \mathrm{ng} / \mathrm{ml} 8$ hours after admission, and 2.89 $\mathrm{ng} / \mathrm{ml} 12$ hours after admission (cutoff at $0.03 \mathrm{ng} / \mathrm{ml}$ ). The ST segment elevation was persistent after tPA treatment. However, the patient experienced a new chest pain within 
ten minutes. Afterwards, the glycerol trinitrate infusion was started, and the pain finally resolved. After an hour, the ST segment elevation was regressed.

After two days, the patient underwent coronary angiography using the standard right femoral Judkins technique. The left coronary angiogram showed that one artery arose from the left sinus of valsalva and continued as a single LAD. No obvious LCX was demonstrated, even after taking repeated coronary angiograms With several different views (Figure 2). The angiogram showed the characteristic focal myocardial bridge in the mid LAD. The RCA was normally, originating from the right sinus of valsalva. It was a dominant RCA that ascended the posterior atrioventricular free groove beyond the crux. The LCX originated from the proximal part of the RCA (Figure 3). It was supported by the inferior and posteriolateral walls of the left ventricle. No significant fixed stenosis was observed in the coronary arteries. A significant narrowness in systole was seen at the midportion of the LAD, where the myocardial bridge was observed.

The patient was diagnosed as having an LCX origin anomaly and a myocardial bridge in the LAD. Non-surgical management was the primary treatment considered for this situation. After two days of clinical follow-up, the patient was discharged with conventional anti-anginal (beta-blocker, statin) and antiplatelet (acetylsalicylic acid) medication.

\section{DISCUSSION}

Congenital coronary artery anomalies are rare but can lead to angina pectoris, myocardial infarction, ventricular tachycardia, ventricular fibrillation, syncope and sudden death. The pathophysiological mechanisms of these clinical phenomena remains unclear. Information on the development of atherosclerosis in patients with coronary anomalies is limited, and these anomalies do not appear to

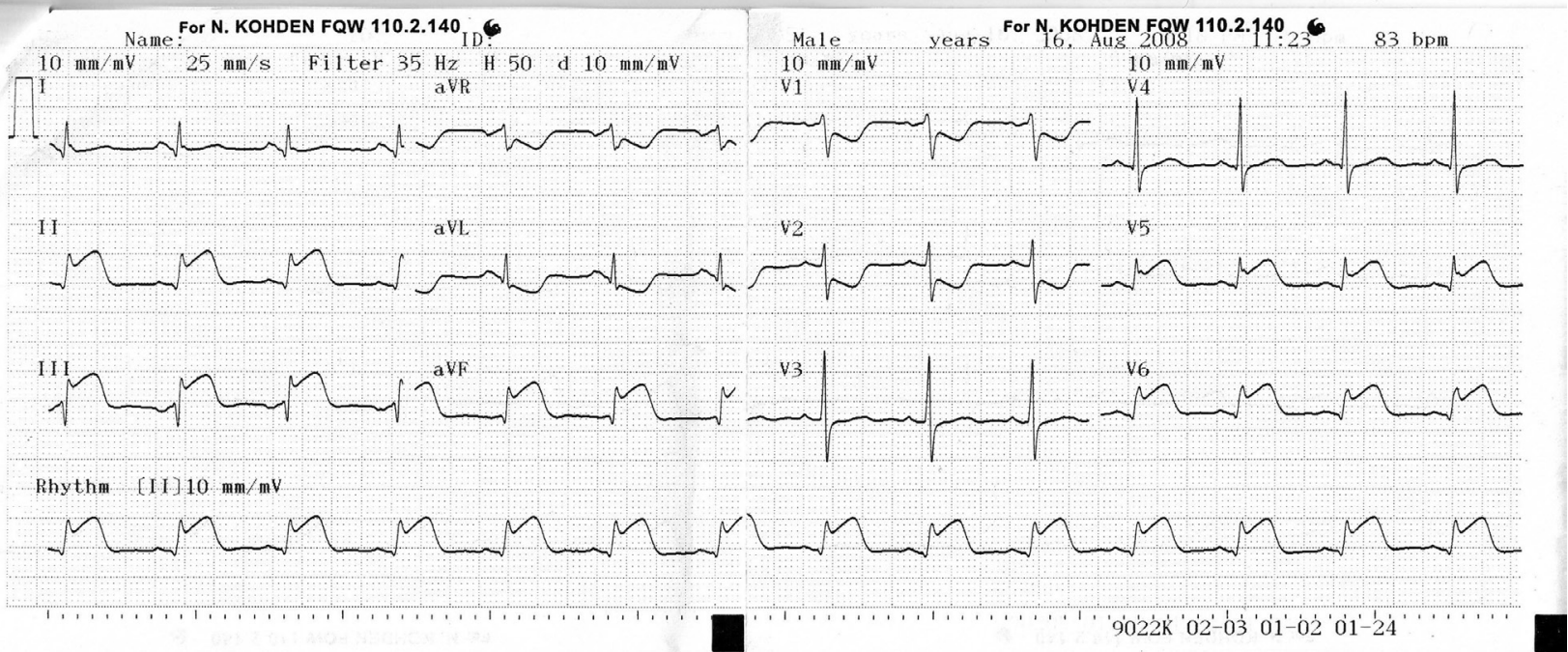

Figure 1 - Electrocardiogram (ECG) showing D2-D3-aVF-V5 and V6 ST- segment elevation.

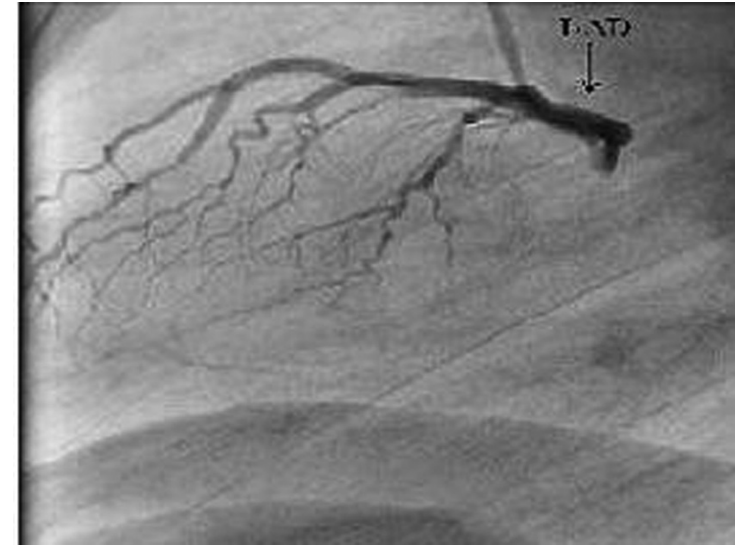

Figure 2 - Coronary angiography from the left lateral view, not showing the circumflex artery.

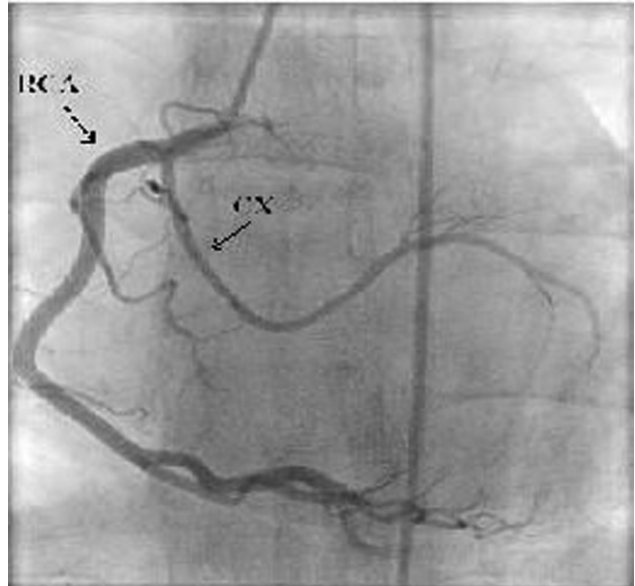

Figure 3 - Anomalous circumflex arising from the right coronary artery. 
be associated with an increased risk for the development of coronary atherosclerosis. However, previous authors have not always agreed on this finding. The proximal/retroaortic portion of the anomalous LCX is more likely to develop obstructive atherosclerotic disease than other coronary vessels. Potential mechanisms explaining this finding include altered flow patterns in such vessels due to angulated take off from the aortic sinus and a subsequent tortuous route that predisposes to atherosclerosis. ${ }^{5,6}$ Moreover, Samarendra et al. reported an earlier and greater degree of atherosclerotic narrowing of the anomalous artery as compared to the other coronary arteries in the same patients, as well as to nonanomalous circumflex arteries of ageand gender-matched control subjects with similar clinical characteristics. $^{\text {? }}$

Some studies have revealed a successful coronary thrombolysis with streptokinase or tissue plasminogen infusion that showed normal coronary arteries on angiography. ${ }^{8,9}$

Possible mechanisms of myocardial infarctions with normal coronary arteries could include spasms of the coronary artery, coronary endothelial damage due to smoking, hypercoagulable states, coronary thrombosis or embolism. ${ }^{3,10}$ Other predisposing factors, such as this case of altered flow patterns related to retroaortic portion anomalous LCX and a muscular bridge, make it very hard to find the etiologic reason(s) of an infarction.

In this case, there may be several factors contributing to STEMI. We suggest that this case occurred due to thrombosis due to endothelial damage by smoking, and also due to spasms of the anomalous LCX. After early antithrombotic and fibrinolytic therapy, the patient's pain was reduced but continued. In addition, he had a new pain in his chest, and the ST elevation was still ongoing. He dramatically relaxed after the IV nitrate therapy within five minutes. Coronary artery spasm is a dynamic and reversible occlusion of an epicardial coranary artery caused by the focal constriction of smooth muscle cells within the arterial wall. Such spasms can also be caused by smoking. Although the ST segment elevation is often striking in patients experiencing these spasms, it rapidly reverts to normal when the pain disappears spontaneously or due to nitroglycerin.

We excluded the hypothesis of STEMI due to a muscular bridge in the mid LAD. Muscular bridges have been associated with angina, arrhythmia, depressed LV function, myocardial stunning and sudden cardiac death in some cases. Nitrates should be avoided in the medical treatment of bridges because they may worsen symptoms. Also, in this case, the infarct area was appropriate for the anomalous LCX.

Coronary artery anomalies are evaluated using catheter-based angiography. During coronary angiography, the precise course of the anomalous vessel may be difficult to delineate due to its complex three-dimensional geometry shown in two dimensions fluoroscopically. Multidetector row-computed tomography (MDCT) is a non-invasive imaging technique that could be an alternative to conventional coronary angiography for screening the anomalous vessels of coronary arteries because of its excellent spatial resolution, which is very important for detecting the relationship between anomalous vessels with great arteries and cardiac structures. ${ }^{11}$

We excluded the hypothesis of atherosclerotic change due to altered flow patterns related to the retroaortic portion anomalous LCX. There were no signs of atherosclerotic processes during angiography, and the patient was only 37 years old. Except for smoking, he had no other classic risk factors of CAD.

\section{REFERENCES}

1. Yamanaka O, Hobbs RE. Coronary artery anomalies in 126,595 patients undergoing coronary arteriography. Cathet Cardiovasc Diagn. $1990 ; 21: 28-40$

2. Taylor AJ, Rogan KM, Virmani R. Sudden cardiac death associated with isolated congenital coronary artery anomalies. J Am Coll Cardiol. 1992;20:640-7.

3. Wilkins CE, Betancourt B, Mathur VS, Massumi A, De Castro CM, Garcia E, et al. Coronary artery anomalies: a review of more than 10,000 patients from the Clayton Cardiovascular Laboratories. Tex Heart Inst J. 1988;15:166-73.
4. Giroux R, Giroux SK. Myocardial infarction with normal or near normal coronary arteries: late outcome of seven patients. Can J Cardiol. 2000;16:162-6.

5. Garg N, Tewari S, Kapoor A, Gupta DK, Sinha N. Primary congenital anomalies of the coronary arteries: a coronary arteriographic study. Int J Cardiol. 2000;74:39-46.

6. West NE, McKenna CJ, Ormerod O, Forfar JC, Banning AP, Channon KM. Percutaneous Coronary Intervention With Stent Deployment in Anomalously-Arising Left Circumflex Coronary Arteries. Catheterization and Cardiovascular Interventions. 2006;68:882-90. 
Selcoki Y et al.

7. Samarendra P, Kumari S, Hafeez M, Vasavada BC, Sacchi TJ. Anomalous circumflex coronary artery: benign or predisposed to selective atherosclerosis. Angiology. 2001;52:521-6.

8. Verheugt FW, ten Cate JW, Sturk A, Imandt L, Verhorst PM, van Eenige $\mathrm{MJ}$, et al. Tissue plasminogen activation activity and inhibition in acute myocardial infarction and angiographically normal coronary arteries. Am J Cardiol. 1987;59:1075-9.

9. Anderson JL, Marshall HW, White RS, Datz F. Streptokinase thrombolysis for acute myocardial infarction in young adults with normal coronary arteries. Am Heart J. 1983;106:1437-8.
10. Da Costa A, Isaaz K, Faure E, Mourot S, Cerisier A, Lamaud M. Clinical characteristics, aetiological factors and long-term prognosis of myocardial infarction with an absolutely normal coronary angiogram; a 3-year follow-up study of 91 patients. Eur Heart J. 2001;22:1459-65.

11. Kacmaz F, Ozbulbul NI, Alyan O, Maden O, Demir AD, Balbay Y, et al. Imaging of coronary artery anomalies: the role of multidetector computed tomography. Coron Artery Dis. 2008;19:203-9. 